Original article

\title{
Psychiatric comorbidity in African patients with epilepsy - Experience from Sierra Leone
}

\author{
Tenema M'bayo ${ }^{\mathrm{a}, 1}$, Michal Tomek ${ }^{\mathrm{b}, 1, *}$, Clifford Kamara ${ }^{\mathrm{a}}$, Durodami Radcliffe Lisk ${ }^{\mathrm{a}}$ \\ ${ }^{a}$ College of Medicine and Allied Health Sciences, University of Sierra Leone, Freetown, Sierra Leone \\ ${ }^{\mathrm{b}}$ Department of Medicine, Basildon E' Thurrock University Hospitals NHS Foundation Trust, Basildon, United Kingdom
}

\section{A R T I C L E I N F O}

\section{Article history:}

Received 29 June 2016

Accepted 5 December 2016

Available online 26 January 2017

\section{Keywords:}

Epilepsy

Seizure

Depression and/or anxiety

Sub-Saharan Africa

\begin{abstract}
A B S T R A C T
Objective: Epilepsy is associated with a significant burden of psychiatric comorbidity, including depression and anxiety disorders. However, paucity of data exists regarding the impact of epilepsy on mental health of patients in the setting of sub-Saharan Africa, where these comorbidities are underrecognized and under-treated. We carried out a cross-sectional descriptive study to investigate the prevalence and determinants of depression and anxiety among people with epilepsy in Sierra Leone. Method: A screening tool previously validated in the primary healthcare setting in Zambia was administered to adult patients in our epilepsy clinics in Freetown and Kenema, Sierra Leone. In addition, various socio-demographic and clinical characteristics were recorded for each patient.

Results: A total of 142 patients were included. The mean screening score was 16.3 out of 40, with 39 (27.5\%) patients scoring above the diagnostic cut-off point for anxiety and/or depression. Variables showing a significant association with the presence of psychiatric comorbidity included female gender $(p=0.015)$, seizure frequency of $>2$ per month $(p=0.001)$, and self-reporting of sedation and/or dizziness as side effects of anti-epileptic medications $(p=0.006)$.

Conclusion: Symptoms of anxiety and depression are common in epilepsy patients in Sierra Leone. Given the significant negative impacts of such comorbidity on those affected, primary healthcare workers in sub-Saharan countries should be trained to inquire about anxiety and depression symptoms in epilepsy patients, and implementation of screening programs should be considered.

๑ 2017 Indian Epilepsy Society. Published by Elsevier, a division of RELX India, Pvt. Ltd. All rights reserved.
\end{abstract}

\section{Introduction}

Epilepsy is one of the commonest neurological disorders, with approximately 70 million people affected worldwide. ${ }^{1}$ While a significant burden of morbidity is directly related to the physical effects of seizures, epilepsy is also associated with a plethora of psychological, social and economic consequences for those affected. As such, epilepsy can have a greater impact on a person's quality of life than many other chronic conditions. ${ }^{2,3}$

It is estimated that $80 \%$ of people with epilepsy (PWE) live in low-income regions such as sub-Saharan Africa, where the prevalence of the condition is substantially higher than in the Western world. ${ }^{1}$ In this setting, the effects of epilepsy on

Abbreviations: PWE, people with epilepsy; SL, Sierra Leone; AED, anti-epileptic drugs; DSM, Diagnostic and Statistical Manual.

* Corresponding author at: Department of Medicine, Basildon \& Thurrock University Hospitals NHS Foundation Trust, Basildon SS16 5NL, United Kingdom.

E-mail address: michal.tomek@cantab.com (M. Tomek).

${ }^{1}$ Shared First Authorship. individuals and their communities can be particularly far-reaching. The condition is commonly associated with misunderstanding and fear, often being perceived as a mental illness, contagious disease or demonic manifestation, with resultant stigmatization and social discrimination. ${ }^{4}$ Furthermore, due to the limited human and material resources, epilepsy is under-diagnosed and options for treatment limited, contributing to high prevalence of poorly controlled seizures and encouraging potentially harmful traditional practices. ${ }^{5}$

Co-morbid mental health conditions including depression and anxiety disorders are common in epilepsy, with reported prevalence rates ranging from $15 \%$ to $60 \%$ worldwide. ${ }^{6,7}$ These can have profound negative impacts on the affected individuals' social functioning and quality of life. In fact, depression has been demonstrated to produce a stronger effect on quality of life than seizure frequency. ${ }^{8-10}$ Seizure control may also be affected; depression has been associated with higher levels of perceived seizure severity, ${ }^{11}$ as well as with increased seizure frequency and the risk of persistent disabling seizures. ${ }^{12,13}$ Furthermore, history of psychiatric illness more than doubles the likelihood of the 
patient becoming refractory to anti-epileptic drugs (AED). ${ }^{14}$ Importantly, presence of depression and anxiety symptoms has been associated with suicidal tendencies in $\mathrm{PWE},{ }^{15}$ with suicide accounting for $11-33 \%$ of deaths in PWE. ${ }^{16}$

There is paucity of data regarding psychiatric co-morbidities in epilepsy in the setting of sub-Saharan Africa. While variable prevalence rates comparable to those in the Western world have been reported, under-diagnosis and under-treatment are common. ${ }^{17-19}$ This was strikingly highlighted in a recent Zambian study by Mbewe et al., who identified only $1 \%$ rate of diagnosis of psychiatric co-morbidity in a group of patients receiving epilepsy care, while retrospective analysis revealed presence of depression and/or anxiety symptoms in $60 \%$ of these. ${ }^{19}$ Given that the majority of epilepsy care in sub-Saharan Africa is provided by primary healthcare workers with extremely limited training in either neurology or psychiatry, coupled with the unique socio-cultural and economic challenges in the region, the barriers to effective recognition and treatment of co-morbid psychiatric conditions among PWE here are greater than elsewhere.

We carried out a pilot study investigating the prevalence and determinants of depression and anxiety in PWE in Sierra Leone $(\mathrm{SL})$, where this topic has previously not been investigated. Exploring the complex interplay between epilepsy and mental health disorders is crucial in improving quality of epilepsy care and tackling the notion of mental illness in epilepsy as a neglected public health domain in the sub-Saharan setting.

\section{Methods}

This cross-sectional descriptive study was carried out in the cities of Freetown and Kenema, SL. The study data were collected during the period of 3rd March to 22nd April 2014 at outpatient clinics held in both cities. Connaught Hospital in Freetown was included in the study as its epilepsy clinic has the highest caseload of patients in the country and represents a predominantly urban population, while Kenema Government Hospital has the highest patient attendance of all the provincial outreach clinics and involves a more rural population.

The study population consisted of patients who attended either of the outpatient clinics and fulfilled the following inclusion criteria: (i) age $\geq 18$ years, (ii) documented history of epilepsy for a minimum of preceding six months, with the diagnosis made by a qualified clinician. The following patients were excluded from the study: (i) patients who already had a diagnosis of a psychiatric disorder or who were receiving treatment for a psychiatric disorder, (ii) patients refusing to be interviewed.

Participants meeting the inclusion criteria were informed about the purpose and objectives of the study and verbal consent was obtained prior to data collection. Literate patients were given our structured screening questionnaire to fill, while illiterate patients were interviewed and had their forms filled in for them. The data collection form we used is a 10-item screening questionnaire designed for the detection of anxiety and depression. This had been developed for use in the primary healthcare setting in a study in Zambia, and was validated using diagnostic criteria for depression and anxiety disorders in the Diagnostic and Statistical Manual version four (DSM-IV), which was current at the time. ${ }^{20}$ It contains 10 items, each scored from 1 to 4 according to symptom frequency, giving a total score range of $10-40$, as shown in Appendix 1. Its relative brevity makes this tool optimal for use in the busy primary care setting, and we felt it was better suited to the purposes of our study in comparison to a number of other available tools, which screen for depression only. Furthermore, we considered it appropriate for use in Sierra Leone, given the significant socioeconomic similarities with Zambia, where the questionnaire had been developed.
In addition, the following demographic and clinical characteristics were also recorded for each patient: age, sex, religion, marital status, level of education, duration of epilepsy (in years), seizure frequency (per month), type of drug treatment (monotherapy or polytherapy), name of antiepileptic drug(s), and self-reported side effect(s).

Chi-squared test was then used to compare the above variables between individuals with anxiety/depression and those without.

Our study was approved by the Community Health Department Research Committee of the College of Medicine and Allied Health Sciences in Freetown, Sierra Leone.

\section{Results}

In total, 142 patients were included in the study, with 83 and 59 interviewed at the Freetown and Kenema clinics, respectively. The response rate for the questionnaires administered to the selected participants was $100 \%$.

\subsection{Demographics}

Of the total of 142 patients, 78 (54.9\%) were male and 64 (45.1\%) were female. The age range for the total sample was $18-82$ years, with a mean age of 29.7 years ( $S D \pm 12.6$ years). The modal age group was $18-25$ years, with $81(57.0 \%)$ patients within that age group. Varied levels of educational background were observed, with patients who had achieved primary education (in full or in part) and those who had completed or were enrolled in senior secondary school forming the largest group; 40 (28.2\%) were in primary and 37 (26.0\%) in senior secondary school. Regarding religious views, $87(61.3 \%)$ patients were Muslim and 55 (38.7\%) Christian. 31 (21.8\%) patients were married, 102 (71.8\%) were single, and 9 (6.3\%) were separated, divorced, or widowed.

\subsection{Screening tool scores}

The score considered significant for detection of anxiety and depression on the screening tool was 18 , identical to the original study. ${ }^{20}$ In the total sample, the mean score on our screening questionnaire was 16.3 ( $\mathrm{SD} \pm 4.7$ ), with a range from 10 to 31.39 (27.5\%) patients scored above the screening cut-off point.

\subsection{Clinical characteristics}

The mean duration of epilepsy in our patients was 10.5 years, with a range of 0.5-60 years. Recorded seizure frequency ranged from daily seizures to 1 per year. Regarding pharmacological treatment, five antiepileptic drugs were prescribed in the clinics in Freetown and Kenema. Phenobarbitone was the most commonly used drug, being prescribed in 121 (85.2\%) patients, either alone or in combination with another AED. 12 patients (8.5\%) were on phenytoin, $10(7.0 \%)$ on carbamazepine, $3(2.1 \%)$ on sodium valproate and 2 (1.4\%) on lamotrigine. 134 (94.4\%) patients were treated with single AED, while 8 (5.6\%) were on polytherapy.

The most commonly reported side effects included sedation $(N=61,43.0 \%)$, dizziness $(N=13,9.2 \%)$, both sedation and dizziness $(N=13,9.2 \%)$, and headache (with co-existent sedation; $N=1,0.7 \%$ ). No side effects were reported in 55 (38.7\%) patients.

When comparing the anxiety/depression group with the nonanxiety/depression group, the following showed statistically significant association with the presence of psychiatric comorbidity: female gender $(p=0.015)$, seizure frequency of $>2$ per month $(p=0.001)$, and self-reporting of sedation and/or dizziness as side effects of AED $(p=0.006)$. 
Table 1

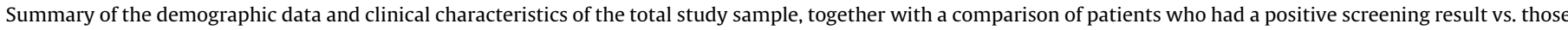
who screened negative.

\begin{tabular}{|c|c|c|c|c|}
\hline & $\begin{array}{l}\text { Total sample } \\
N(\%)\end{array}$ & $\begin{array}{l}\text { Screening } \\
\text { Positive } \\
N(\%)\end{array}$ & $\begin{array}{l}\text { Screening } \\
\text { Negative } \\
N(\%)\end{array}$ & $p$-Value \\
\hline Sex & & & & $0.015^{*}$ \\
\hline M & 78 (54.9) & $15(38.5)$ & $63(61.1)$ & \\
\hline $\mathrm{F}$ & $64(45.1)$ & $24(61.5)$ & $40(38.8)$ & \\
\hline Formal education & & & & - \\
\hline None & $27(19.0)$ & $6(15.4)$ & $21(20.4)$ & \\
\hline Primary & $40(28.2)$ & $13(33.3)$ & $27(26.2)$ & \\
\hline Secondary & $57(40.1)$ & $17(44)$ & $40(38.8)$ & \\
\hline Tertiary & $18(12.7)$ & $3(7.6)$ & $15(14.6)$ & \\
\hline Religion & & & & 0.464 \\
\hline Muslim & $87(61.3)$ & $22(56.4)$ & $65(63.1)$ & \\
\hline Christian & $55(38.7)$ & $17(43.6)$ & $38(36.8)$ & \\
\hline Marital status & & & & 0.385 \\
\hline Single $^{a}$ & $111(78.2)$ & $31(79.5)$ & $80(77.7)$ & \\
\hline Married & $31(21.8)$ & $8(20.5)$ & $23(22.3)$ & \\
\hline Location & & & & 0.761 \\
\hline Freetown & $83(58.8)$ & $22(56.4)$ & $61(59.2)$ & \\
\hline Kenema & $59(41.5)$ & $17(43.6)$ & $42(40.1)$ & \\
\hline Duration of epilepsy & & & & 0.337 \\
\hline $0.5-10$ years & $82(57.7)$ & $20(51.2)$ & $62(60.2)$ & \\
\hline$>10$ years & $60(42.3)$ & $19(48.7)$ & $41(39.8)$ & \\
\hline No. of seizures/month & & & & $0.001^{*}$ \\
\hline$\leq 2$ & $113(79.6)$ & $24(61.5)$ & $89(86.4)$ & \\
\hline$>2$ & $29(20.4)$ & $15(38.5)$ & $14(13.6)$ & \\
\hline AED & & & & 0.902 \\
\hline Phenobarbitone & $121(85.2)$ & $33(84.5)$ & $88(85.3)$ & \\
\hline Other & $21(14.8)$ & $6(15.4)$ & $15(14.6)$ & \\
\hline Pharm. treatment & & & & 0.142 \\
\hline Monotherapy & $134(94.4)$ & 35 (89.7) & $99(96.1)$ & \\
\hline Polytherapy & $8(5.6)$ & $4(10.3)$ & $4(3.9)$ & \\
\hline Drug side effects & & & & $0.006^{*}$ \\
\hline Sedation/dizziness & $87(61.3)$ & $31(79.5)$ & $56(54.4)$ & \\
\hline None & $55(38.7)$ & $8(20.5)$ & $47(45.6)$ & \\
\hline
\end{tabular}

a Includes separated, divorced and widowed.

Statistically significant.

Summary of the demographic data and clinical characteristics of the total study sample, as well as a comparison of patients according to their screening result, is shown in Table 1.

\section{Discussion}

Epilepsy is associated with a significant burden of psychiatric co-morbidity, in particular anxiety disorders and depression. The reported prevalence rates of these mental health disorders in PWE in sub-Saharan Africa are variable, with scant data regarding potential predisposing factors and causative mechanisms. In this cross-sectional descriptive study we investigated the link between epilepsy and mental health disorders in Sierra Leone.

Using a structured screening questionnaire previously validated by Mbewe et al. in Zambia, we found a $28 \%$ prevalence rate of anxiety disorder and/or depression among adults with epilepsy in SL. Interestingly, our findings contrast the considerably higher figure of $49 \%$ reported in the former study, where the same diagnostic cut-off point was used. However, results from studies in Nigeria were comparable to ours, with reported prevalence range of $26-31 \%{ }^{17,18}$ Importantly, our findings suggest that the rates of psychiatric comorbidity are comparable to those reported in Western countries. ${ }^{7,20,21}$

Positive screening result for anxiety and/or depression showed significant association with female gender, with a sex ratio of 3:2 in the group screening positive. This is in keeping with previously reported data, ${ }^{22}$ and may reflect the well-documented female preponderance among patients with depression in the general population. ${ }^{23}$ However, we did not find any significant association with other socio-demographic factors including marital status, religious beliefs, physical location, or the educational background of the patient. Nevertheless, among those screening negative there were proportionately fewer participants who only had a primary education and twice as many who had achieved a tertiary education, as compared to the group screening positive. This may imply a potential role of higher educational achievements as a protective factor in reducing the risk of anxiety and/or depression.

Certain disease characteristics including seizure frequency and duration of epilepsy have previously been associated with the presence of anxiety and depression symptoms. Data from Western countries have demonstrated a prevalence range of $20-60 \%$ in patients with recurrent seizures, as compared to $10-20 \%$ in patients with well-controlled epilepsy. ${ }^{7,24,25}$ In the present study we demonstrated a significant association between having more than two seizures per month and screening positive for anxiety and/or depression. In contrast, we did not replicate the findings from Nigeria, where an association between having epilepsy for more than 10 years and the risk of developing depressive symptoms has been reported. ${ }^{17}$ This may however be due to the use of the Hospital Anxiety and Depression Scale (HADS) in the latter study, which assessed for anxiety and depression separately, in contrast to the non-specific screening tool used in our data collection.

With regards to treatment, phenobarbitone was the most commonly prescribed anti-epileptic medication in our patient group, being used in $85 \%$ of participants either alone or in combination with another AED. The use of phenobarbitone as a principal AED is in fact widespread throughout sub-Saharan Africa, reflecting its low cost, availability, and simple once-daily dosing. 
Notably, barbiturates including phenobarbitone and primidone have been reported to cause depression as a side-effect in a dosedependent manner, in contrast to agents such as phenytoin, ethosuximide, carbamazepine, sodium valproate, and lamotrigine. $^{26,27}$ Notwithstanding, we did not observe any significant relationship between phenobarbitone use and a positive screening result for anxiety and/or depression. Equally, the previously reported role of AED polytherapy as a risk factor for psychiatric co-morbidity has not been identified in our results. ${ }^{17,27}$

Importantly however, patients screening positive were significantly more likely to report sedation and dizziness as side effects of their treatment. It may be that these self-reported symptoms were true pharmacological side effects, contributing in a causal manner to the development of anxiety and/or depression through negative effects on the individual's sense of well-being. Nevertheless, it is also plausible that their presence may be a consequence, rather than cause, of an underlying anxiety or depression; the affected patients may be more likely to experience and/or over-report nonspecific drug effects, or the reported symptoms may represent primary psychosomatic manifestations of the underlying psychiatric disturbance, falsely attributed by the patients to their antiepileptic treatment.

In keeping with the diverse socio-demographic and clinical factors associated with the presence of depression and anxiety in epilepsy, it is apparent that the psychopathogenic causation is multifactorial. Feelings of hopelessness and helplessness, core features of depression, may for example be triggered by uncontrolled epilepsy with high seizure frequency and the lack of adequate epilepsy care, respectively. This may be further contributed to by interictal chronic ill health due to AED side effects or seizure-related physical injury such as severe burns, while symptoms of anxiety may be evoked by apprehension over potential future occurrence of such events. Moreover, seizurerelated social embarrassment and stigma with consequent disruption in social, academic and occupational functioning can further perpetuate both anxiety and depression. Notably however, it has been observed that patients with epilepsy are at an increased risk of depression as compared to the general population even prior to the onset of any clinical manifestations of any seizure disorder. ${ }^{28,29}$ This suggests the intriguing possibility that the link between epilepsy and depression may not be limited to a simple unidirectional causation; the two disorders may in fact share the same pathogenic mechanism, with the common serotonergic pathway postulated as a possible culprit. ${ }^{30}$

The findings of our study are limited by the cross-sectional design and small sample size. Furthermore, the diagnostic tool is non-specific and does not allow for reliable distinction between anxiety and depression. However, we felt that it was adequate for the purposes of carrying out a simple explorative study in Sierra Leone and assessing potential need for future screening programs. First, it had previously been validated as an effective screening instrument in another sub-Saharan country with similar demographic and socio-cultural background to Sierra Leone. Second, most other available questionnaires are considerably longer, with higher levels of complexity resulting in potentially greater susceptibility to cultural and languagerelated barriers. Third, its simple structure translates into minimal training requirements and time commitment on behalf of the administering healthcare worker in the busy and underresourced primary healthcare services within sub-Saharan Africa, allowing for realistic incorporation into routine patient assessment and enabling potential screening programs. Such endeavors will be essential if better recognition and treatment of psychiatric comorbidity are to be achieved in an effort to improve quality of life and reduce suicide rates in PWE in countries such as Sierra Leone.

\section{Conclusion}

In conclusion, our results show that anxiety and depression symptoms are common in PWE in Sierra Leone. We demonstrate that female gender, poorly controlled seizures, and self-reported antiepileptic medication side effects are significant determinants of the presence of psychiatric comorbidity. Primary healthcare workers in countries of the sub-Saharan region should be trained to inquire about symptoms of anxiety and depression in epilepsy patients, and consideration should be given to implementing screening programs using validated questionnaires. Further data, in particular from controlled studies, will be needed to advance our understanding of the multifaceted interplay between epilepsy and psychiatric comorbidity in Sierra Leone and other low-income countries.

\section{Conflicts of interest}

The authors have none to declare.

\section{Appendix 1. Screening tool}

\begin{tabular}{|c|c|c|c|c|}
\hline Statement & $\begin{array}{l}\text { All the } \\
\text { time }\end{array}$ & $\begin{array}{l}\text { Very } \\
\text { often }\end{array}$ & Sometimes & Seldom \\
\hline \multicolumn{5}{|l|}{ Over the past one month } \\
\hline $\begin{array}{l}\text { 1. Are you thinking about too many } \\
\text { things or thinking too much }{ }^{\mathrm{a}}\end{array}$ & 4 & 3 & 2 & 1 \\
\hline 2. Are you feeling depressed? & 4 & 3 & 2 & 1 \\
\hline 3. Are you feeling anxious? ${ }^{\mathrm{a}}$ & 4 & 3 & 2 & 1 \\
\hline 4. Is your sleep disturbed? ${ }^{\mathrm{b}}$ & 4 & 3 & 2 & 1 \\
\hline $\begin{array}{l}\text { 5. Do you feel it may be better } \\
\text { to die? }\end{array}$ & 4 & 3 & 2 & 1 \\
\hline $\begin{array}{l}\text { 6. Do you get less pleasure from } \\
\text { things? Loss of pleasurable } \\
\text { feelings }\end{array}$ & 4 & 3 & 2 & 1 \\
\hline $\begin{array}{l}\text { 7. Do you have difficulty in } \\
\text { concentrating? }^{a}\end{array}$ & 4 & 3 & 2 & 1 \\
\hline $\begin{array}{l}\text { 8. Have you been experiencing } \\
\text { increased heartbeat for the } \\
\text { past one month? }\end{array}$ & 4 & 3 & 2 & 1 \\
\hline $\begin{array}{l}\text { 9. Do you experience less } \\
\text { desire for food? }\end{array}$ & 4 & 3 & 2 & 1 \\
\hline $\begin{array}{l}\text { 10. Do you feel tired for no } \\
\text { apparent reason? }\end{array}$ & 4 & 3 & 2 & 1 \\
\hline
\end{tabular}

a Items identify anxiety, while the other items identify depression.

b Item may be related to both conditions.

Reproduced from Ref. $^{20}$

\section{References}

1. Ngugi AK, Bottomley C, Kleinschmidt I, Sander JW, Newton CR. Estimation of the burden of active and life-time epilepsy: a meta-analytic approach. Epilepsia. 2010;51:883-890.

2. International League Against Epilepsy. Epilepsy - out of the shadows: European declaration on epilepsy. Epilepsia. 2003;44(suppl 6):2-3.

3. International League Against Epilepsy. Quality of life: general considerations. Epilepsia. 2003;44(suppl 6):57-58.

4. World Health Organisation. Epilepsy in the WHO African Region: Bridging the Gap. Geneva: WHO; 2004

5. World Health Organisation. Neurological Disorders. Public Health Challenges. Geneva: WHO; 2006.

6. Gilliam F, Mendiratta A, Pack M, Basil W. Epilepsy and common comorbidities: improving the outpatient epilepsy encounter. Epileptic Disord. 2005;7:S27-S33.

7. Jacoby A, Baker GA, Steen N, Potts P, Chadwick DW. The clinical course of epilepsy and its psychosocial correlates: findings from a U.K. Community study. Epilepsia. 1996;37:148-161.

8. Kondziella D, Asztely F. Don't be afraid to treat depression in patients with epilepsy!. Acta Neurol Scand. 2009;119:75-80.

9. Wiegartz P, Seidenberg M, Woodard A, Gidal B, Hermann B. Co-morbid psychiatric disorder in chronic epilepsy: recognition and etiology of depression. Neurology. 1999;53:S3-S8.

10. Gilliam F, Kuzniecky R, Faught E, Black L, Carpenter G, Schrodt R. Patient-validated content of epilepsy-specific quality of life measurement. Epilepsia. 1997;38:233236. 
11. Cramer JA, Blum D, Reed M, Fanning K. The influence of comorbid depression on seizure severity. Epilepsia. 2003;44:1578-1584.

12. Jackson M, Turkington D. Depression and anxiety in epilepsy. J Neurol Neurosurg Psychiatry. 2005;76:i45-i47.

13. Cramer JA, Blum D, Fanning K, Reed M. The impact of comorbid depression on health resource utilization in a community sample of people with epilepsy. Epilepsy Behav. 2004;5:337-342.

14. Hitiris N, Mohanraj R, Norrie J, Sills GJ, Brodie MJ. Predictors of pharmacoresistant epilepsy. Epilepsy Res. 2007:75:192-196.

15. Nuhu FT, Lasisi MD, Yusuf AJ, Aremu SB. Suicide risk among adults with epilepsy in Kaduna, Nigeria. Gen Hosp Psychiatry. 2013;35(5):517-520.

16. Verrotti A, Ciconetti A, Scorrano B, Ferro F. Epilepsy and suicide: pathogenesis, risk factors and prevention. Neuropsychiatr Disord Treat. 2008;4:367-370.

17. Fatoye F, Mosaku KS, Komolafe M, Adewuya AO. Interictal anxiety and depression symptoms in Nigerians with epilepsy: a controlled study. Epilepsy Behav. 2006;9(2):312-316.

18. Okubadejo NU, Danesi MA, Aina OF, Ojini FI, Adeyemi JD, Olorunshola DA. Prospective case-control study of interictal depression and suicidal ideation in Nigerians with epilepsy. Niger Postgrad Med J. 2007;14(3):204-208.

19. Mbewe EK, Uys LR, Birbeck GL. Detection and management of depression and/or anxiety for people with epilepsy in primary health care settings in Zambia. Seizure. 2013;22(5):401-402.

20. Mbewe EK, Uys LR, Nkwanyana NM, Birbeck GL. A primary healthcare screening tool to identify depression and anxiety disorders among people with epilepsy in Zambia. Epilepsy Behav. 2013;27(2):296-300.
21. Mendez MF, Cummings JL, Benson DF. Depression in epilepsy: significance and phenomenon. Arch Neurol. 1986;43:766-770.

22. Ogunrin OA, Obiabo YO. Depressive symptoms in patients with epilepsy: analysis of self-rating and physician's assessment. Neurol India. 2010;58(4): 565-570.

23. Harter MC, Conway KP, Merikangas KR. Association between anxiety disorders and physical illness. Eur Arch Psychiatry Clin Neurosci. 2003;253:313-320.

24. Edeh J, Toone BK. Relationship between interictal psychopathology and the types of epilepsy: results of a survey in general practise. Br J Psychiatry. 1987;151: 95-101.

25. Mendez MF, Cummings JL, Benson DF. Depression in epilepsy: significance and phenomenology. Arch Neurol. 1986;43:766-770.

26. Mula M, Sander JW. Negative effects of antiepileptic drugs on mood in patients with epilepsy. Drug Saf. 2007;30(7):55-569.

27. Adewuya AO, Ola BA. Prevalence of and risk factors for anxiety and depressive disorders in Nigerian adolescents with epilepsy. Epilepsy Behav. 2005;6(3):342347.

28. Fong CG, Hung A. Public awareness, attitude and understanding of epilepsy in Hong Kong special administrative region, China. Epilepsia. 2002;43:311-316.

29. Nubukpo P, Houinato D, Preux PM, Avode G, Clement JP. Anxiety and depression among the epileptics in general population in Benin (Western Africa). Encephale 2004;30:214-219.

30. Kanner AM. Depression in epilepsy: a neurobiologic perspective. Epilepsy Curr. 2005;5:21-27. 